\title{
Protocol
}

\section{Preparation of Cellular Extracts from Xenopus Eggs and Embryos}

\author{
Matthew C. Good ${ }^{1,3}$ and Rebecca Heald 2,3 \\ ${ }^{1}$ Department of Cellular and Developmental Biology and Department of Bioengineering, University of \\ Pennsylvania, Philadelphia, Pennsylvania 19104; ${ }^{2}$ Department of Molecular and Cell Biology, University of \\ California Berkeley, Berkeley, California 94720
}

Cell-free cytoplasmic extracts prepared from Xenopus eggs have been used extensively to recapitulate and characterize intracellular events in vitro. Egg extracts can be induced to transit the cell cycle and reconstitute assembly of dynamic structures including the interphase nucleus and the mitotic spindle. In this protocol, methods are described for preparing crude cytoplasmic extracts from Xenopus eggs and embryos that are arrested in metaphase of the cell cycle. The basic protocol uses unfertilized Xenopus laevis eggs, which are crushed by centrifugation in the presence of EGTA to preserve the natural cytostatic factor (CSF) activity that maintains high levels of Cdk1/cyclin B kinase and metaphase arrest. In the second method, the basic procedure is adapted for Xenopus tropicalis eggs with minor modifications to accommodate differences in frog size, timing of egg laying, and temperature and salt sensitivity. The third variation takes advantage of the synchronous divisions of fertilized $X$. laevis eggs to generate extracts from embryos, which are arrested in metaphase by the addition of nondegradable cyclin B and an inhibitor of the anaphase-promoting complex (APC) that together stabilize Cdk1/cyclin B kinase activity. Because they are obtained in much smaller amounts and their cell cycles are less perfectly synchronized, extracts prepared from embryos are less robust than egg extracts. X. laevis egg extracts have been used to study a wide range of cellular processes. In contrast, $X$. tropicalis egg extracts and $X$. laevis embryo extracts have been used primarily to characterize molecular mechanisms regulating spindle and nuclear size.

MATERIALS

It is essential that you consult the appropriate Material Safety Data Sheets and your institution's Environmental Health and Safety Office for proper handling of equipment and hazardous materials used in this protocol.

RECIPES: Please see the end of this protocol for recipes indicated by $<R>$. Additional recipes can be found online at http://cshprotocols.cshlp.org/site/recipes.

Reagents

\section{Agarose (1.5\% in $0.1 \times \mathrm{MMR})$}

Microwave before using to coat the bottom of a Petri dish. Dishes should be prepared the day before embryo extract preps, covered with $0.1 \times M M R$ and stored at RT. Discard the $0.1 \times M M R$ before use.

$\mathrm{CSF}-\mathrm{XB}<\mathrm{R}>$

This buffer is used for $\mathrm{X}$. laevis eggs and embryos.

${ }^{3}$ Correspondence: bheald@berkeley.edu, mattgood@upenn.edu

From the Xenopus collection, edited by Hazel L. Sive.

(C) 2018 Cold Spring Harbor Laboratory Press

Cite this protocol as Cold Spring Harb Protoc; doi:10.1101/pdb.prot097055 
M.C. Good and R. Heald

CSF-XB+ (CSF-XB supplemented with $10 \mu \mathrm{g} / \mathrm{mL}$ LPC)

Dilute LPC protease inhibitor cocktail 1:1000 into CSF-XB. Prepare fresh and use immediately. This buffer is used for $\mathrm{X}$. laevis eggs and embryos.

CSF-XB solution \#2 for $X$. tropicalis eggs $<\mathrm{R}>$

This buffer is used for X. tropicalis eggs and contains additional EGTA and magnesium chloride.

CSF-XB+ solution \#2 (CSF-XB solution \#2 supplemented with $10 \mu \mathrm{g} / \mathrm{mL} \mathrm{LPC}$ )

Dilute LPC protease inhibitor cocktail 1:1000 into CSF-XB solution \#2. Prepare fresh and use immediately. This buffer is used for X. tropicalis eggs and contains additional EGTA and magnesium chloride.

Cytochalasin D or B (10 mg/mL, Sigma-Aldrich C8273 or Sigma-Aldrich C6762, respectively) Dissolve in DMSO and store in $50 \mu \mathrm{L}$ aliquots at $-20^{\circ} \mathrm{C}$.

Dejelly solution \# 1 for Xenopus laevis eggs $<\mathrm{R}>$

Dejelly solution \#2 for Xenopus tropicalis eggs and Xenopus laevis embryos $<\mathrm{R}>$ Unlike the X. laevis dejelly solution, the X. tropicalis buffer does not contain salts.

Dimethyl sulfoxide (DMSO) (anhydrous, high purity such as Sigma-Aldrich)

Energy mix $(50 \times)<\mathrm{R}>$

Note that some labs do not add energy mix to egg extracts.

Human chorionic gonadotropin (HCG; Sigma-Aldrich CG10) or chorulon (A to Z Vet Supply), at a concentration of $1000 \mathrm{IU} / \mathrm{mL}$

Dissolve in sterile MilliQ $\mathrm{H}_{2} \mathrm{O}$ and store at $4^{\circ} \mathrm{C}$.

LPC protease inhibitor cocktail ( $10 \mathrm{mg} / \mathrm{mL}$ each of leupeptin, pepstatin, chymostatin; EMD Millipore)

Dissolve in DMSO and store in $50 \mu \mathrm{L}$ aliquots at $-20^{\circ} \mathrm{C}$.

Marc's modified Ringer's (MMR; $20 \times)<\mathrm{R}>$

Dilute to desired concentration with MilliQ $\mathrm{H}_{2} \mathrm{O}$ before use.

Mature female Xenopus laevis or Xenopus tropicalis frogs

Frogs are obtained from NASCO. Females are used to obtain eggs as described below.

Mature male Xenopus laevis frogs

Frogs are obtained from NASCO. Males are killed to obtain fresh testes for fertilization to obtain embryos (see Protocol: Isolation and Demembranation of Xenopus Sperm Nuclei [Hazel and Gatlin 2018)].

Pregnant mare serum gonadotropin (PMSG; 200 IU/mL; Prospec HOR-272)

Dissolve in sterile MilliQ $\mathrm{H}_{2} \mathrm{O}$ and store at $4^{\circ} \mathrm{C}$.

Purified proteins: Aliquots of $0.5 \mathrm{mg} / \mathrm{mL}(\sim 13 \mu \mathrm{M}) \Delta 90$-CyclinB1 in XB (Glotzer et al. 1991); $15 \mathrm{mg} / \mathrm{mL}$ $(\sim 750 \mu \mathrm{M})$ human UbcH10-C114S in XB (Rape et al. 2006)

$\mathrm{XB}$ (extract buffer) $<\mathrm{R}>$

Equipment

Beakers, plastic (0.5 and $4 \mathrm{~L})$ and glass $(500 \mathrm{~mL})$

Centrifuge (floor size, high speed, refrigerated) set to $16^{\circ} \mathrm{C}$

Centrifuge tubes (round-bottom $13 \mathrm{~mL}$ polypropylene $16.8 \times 95 \mathrm{~mm}$; Sarstedt 55.518 )

Clinical centrifuge (refrigerated, swinging-bucket) set to either $16^{\circ} \mathrm{C}$ or $25^{\circ} \mathrm{C}$.

Dissection stereomicroscope

Forceps

Ice bucket with ice

Microcentrifuge tubes (1.5 and $2 \mathrm{~mL}$ )

Petri dishes (glass, $6 \mathrm{~cm}$ diameter) 
Plastic containers for frogs (4 and $6 \mathrm{~L}$; Corning) with tight-fitting lids and holes punched for air exchange

Plastic pestle for $1.5 \mathrm{~mL}$ microfuge tube (USA Scientific)

Room $\left(16^{\circ} \mathrm{C}\right)$ or large nonair tight incubator set to $16^{\circ} \mathrm{C}$ for Xenopus laevis

Rotor (swinging bucket Sorvall HB-6) with rubber (Kimble-Chase) and microcentrifuge tube adapters (Sorvall)

Syringes (disposable; $1 \mathrm{~mL}$ )

Syringe needles (18-gauge 1.5 inch length, and 30-gauge, 0.5 inch length)

Transfer pipettes (plastic, draw up to $3.4 \mathrm{~mL}$ per squeeze; Fisher)

Ultracentrifuge tubes (SW-55 ultraclear thin-wall $5 \mathrm{~mL} ; 13 \times 51 \mathrm{~mm}$, Beckman 344057)

\section{METHOD}

Three different extract preparation procedures are outlined, which have been optimized for X. laevis eggs, X. tropicalis eggs, or X. laevis embryos.

\section{Xenopus laevis Egg Extract Procedure}

1. Prime Xenopus laevis females at least $3 \mathrm{~d}$ before extract preparation by injecting $0.5 \mathrm{~mL}$ (100 IU) of PMSG subcutaneously into the region between the top of a hind leg and the cloaca (dorsal lymph sac) using a 30-gauge needle and $1 \mathrm{~mL}$ syringe.

Typically, 3-4 females are used for each extract preparation. Priming the frogs increases egg yield and egg quality. Primed frogs should be used within 2 wk. Depending on hormone source, the injected amount may need to be titrated. If the frogs lay eggs following priming, subsequently reduce the amount injected by $50 \%$.

2. Induce ovulation by injecting primed frogs $16-18 \mathrm{~h}$ before extract preparation time with $0.5 \mathrm{~mL}$ (500 IU) of HCG. Store each frog individually in $2 \mathrm{~L}$ of $1 \times$ MMR in a $4 \mathrm{~L}$ plastic container overnight at $16^{\circ} \mathrm{C}$. On average, each female should lay more than a thousand eggs (Fig. 1A).

Housing frogs individually prevents mixing of egg clutches of variable quality.

3. Remove frogs from containers and analyze egg quality. Good eggs have clearly delineated animal (dark) and vegetal (light) poles. Remove lysed (white and puffy), mottled or abnormal looking eggs from containers using a transfer pipette. Store eggs at $16^{\circ} \mathrm{C}$ until all buffers and supplies are prepared.

Clutches that contain a significant number of eggs $(>2 \%)$ that are activated or lysed (white and puffy appearance) or connected in long strings should not be used.

4. For eggs from three to four females, prepare $1 \mathrm{~L}$ Dejelly solution \#1, $1 \mathrm{~L} \mathrm{XB}$, and $400 \mathrm{~mL}$ CSF-XB. Ten minutes before the extract prep, prepare $100 \mathrm{~mL}$ CSF-XB+, dispense $1 \mathrm{~mL}$ CSF-XB+ to 4 ultracentrifuge tubes, and add $10 \mu \mathrm{L}$ of cytochalasin $\mathrm{D}$ (final concentration of $100 \mu \mathrm{g} / \mathrm{mL}$ ) to each tube. For supplies: trim tips from four transfer pipettes to increase opening diameter to $\sim 2 \mathrm{~mm}$, and leave four uncut. Gather $4 \mathrm{~L}$ plastic and $500 \mathrm{~mL}$ glass beakers and all required reagents and supplies. Make sure that clinical and high-speed centrifuges are set to $16^{\circ} \mathrm{C}$.

One frog typically produces enough eggs to fill one tube.

It is crucial to be prepared for all subsequent steps before starting.

Dejelly and egg-washing steps can be performed at room temperature but extract quality may be higher if steps are performed in a $16^{\circ} \mathrm{C}$ room.

5. In the next steps (6-8), gently pour buffers down the side of the beaker, and swirl eggs while avoiding excess turbulence. Between steps, pour off as much buffer as possible into a 4 L beaker without exposing the eggs to air, which will lyse them. Manipulate eggs carefully and once eggs are dejellied, carry out subsequent washing and centrifugation steps in rapid succession. Throughout the procedure, remove abnormal or lysed eggs with a transfer pipette. 

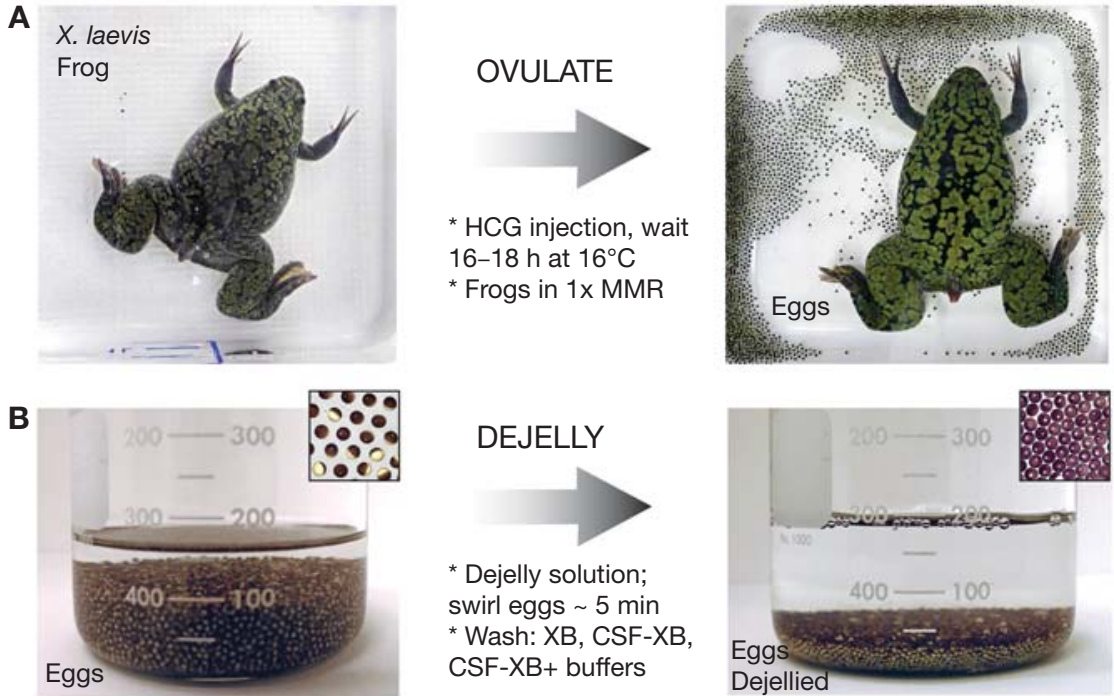

C

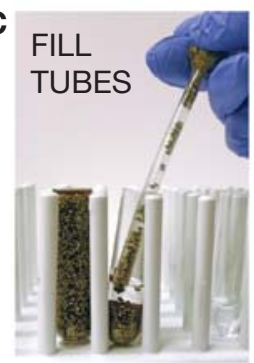

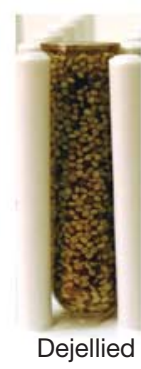

Eggs

* Frogs in $1 \times \mathrm{MM}$

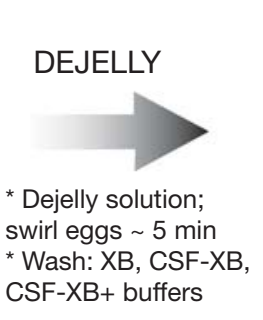

D
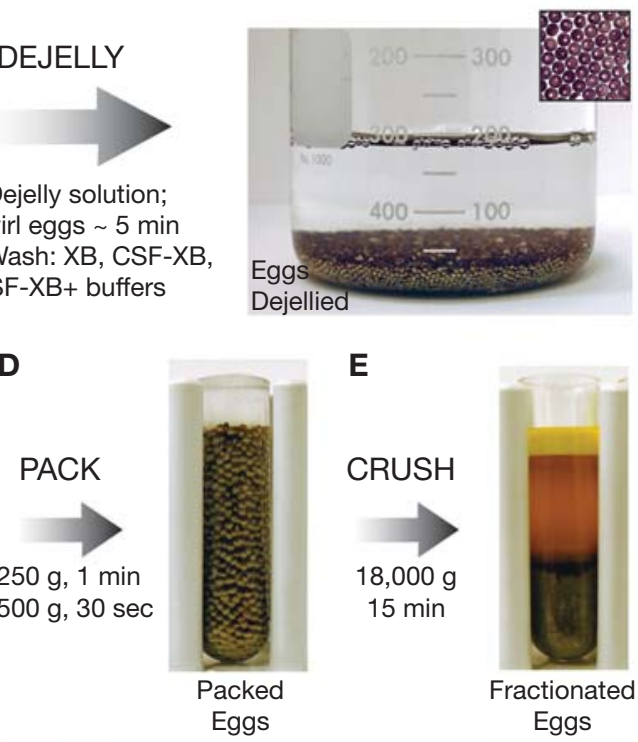

E
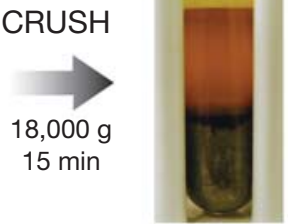

Fractionated

Eggs

$\mathbf{F}$

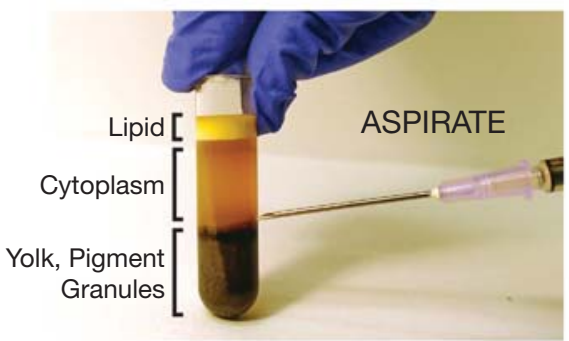

COLLECT

CYTOPLASM

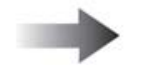

* Add LPC, CytoD,

and Energy Mix

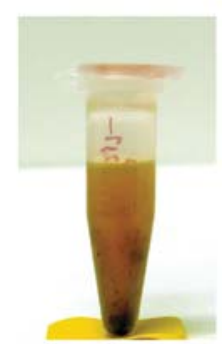

FIGURE 1. Xenopus laevis egg extract preparation. (A) Female frogs induced to ovulate by injection with HCG. Laid eggs are collected $16-18 \mathrm{~h}$ after the injection. $(B)$ Eggs are dejellied using a cysteine solution. The eggs pack tightly together once their jelly coats have been removed. Inset: egg spacing before and after dejelly step. $(C)$ Dejellied eggs are carefully transferred to an ultracentrifuge tube using a plastic transfer pipette whose tip has been cut to create a wider bore. $(D)$ A series of low-speed spins tightly packs eggs without lysing them, allowing excess buffer to be removed. $(E)$ A high-speed spin crushes and fractionates the eggs. $(F)$ The cytoplasm layer is collected by puncturing the tube wall using a needle and syringe. Once aspirated, the cytoplasm is transferred to a new tube and supplemented with additional reagents.

6. Clean the eggs: Pour off $1 \times$ MMR from the plastic container containing laid eggs. Gently pour in 250-500 $\mathrm{mL}$ fresh $1 \times$ MMR and repeat washes until all dirt and debris are removed.

7. Dejelly eggs: Combine best clutches of eggs into a single $500 \mathrm{~mL}$ glass beaker and pour off remaining MMR. Add $\sim 250 \mathrm{~mL}$ of Dejelly solution \#1. Swirl the eggs gently, every $20 \mathrm{sec}$, and every 2 min pour off and replenish the solution. Dejellying is complete once eggs pack together tightly, without gaps (Fig. 1B). The close packing is easiest to discern visually when beaker is tipped at a $45^{\circ}$ angle. Total time to dejelly will vary, but should be around $5 \mathrm{~min}$. Once completed, pour off the dejelly solution and immediately add $\sim 300 \mathrm{~mL}$ of XB.

Alternatively, each egg clutch can be transferred to an individual beaker and dejellied and washed separately using smaller buffer volumes. 
8. Wash eggs: Pour off the first addition of $X B$ and wash again with $300 \mathrm{~mL}$. Pour off the $\mathrm{XB}$ and wash two times with $\sim 200 \mathrm{~mL}$ of CSF-XB. Pour off the CSF-XB and add $100 \mathrm{~mL}$ of CSF-XB+. At this point the eggs should appear very clean with their dark animal poles facing up. Sort one final time to remove any lysed or abnormal eggs.

9. Transfer eggs very carefully to prepared ultracentrifuge tubes containing CSF-XB+ and cytochalasin. Use a trimmed transfer pipette, and avoid exposing the eggs to air by first drawing up $0.5 \mathrm{~mL}$ of CSF-XB+ buffer and then gently drawing up the eggs, and expelling them below the liquid surface. Typically 2-3 fillings of the transfer pipette are required to fill one tube with eggs (Fig. 1C).

Do not overfill tubes, which exposes eggs to air.

10. Packing spin: Using forceps, place each tube filled with eggs inside a $13 \mathrm{~mL}$ Sarstedt tube. Transfer tubes to clinical centrifuge at $16^{\circ} \mathrm{C}$. Balance rotor and spin at $250 \mathrm{~g}$ for $1 \mathrm{~min}$, and then at $500 \mathrm{~g}$ for an additional $30 \mathrm{sec}$ to pack the eggs (Fig. 1D). After spinning, remove all buffer from the top of the eggs using a transfer pipette.

This step prevents buffer from diluting the extract, so it is worth sacrificing a few eggs to ensure that all buffer is removed.

11. Crushing spin: Transfer tubes filled with packed eggs to a Sorvall HB-6 rotor with rubber adapters in a high-speed centrifuge. Crush and fractionate the eggs by spinning at $18,000 \mathrm{~g}$ for $15 \mathrm{~min}$ at $16^{\circ} \mathrm{C}$ (Fig. 1E).

12. Collect cytoplasm: Immediately upon completion of centrifugation, remove thin-wall tubes containing fractionated eggs from Sarstedt tubes and place them on ice. Using an 18-gauge needle attached to a $1 \mathrm{~mL}$ syringe, puncture the thin-wall tube at the bottom of the cytoplasmic layer (Fig. 1F). Aspirate the cytoplasm without taking up any of the surrounding yolk or lipid layers. Remove the needle and expel the cytoplasm into a prechilled tube on ice.

To avoid piercing your finger and to keep the tube cool while withdrawing the extract, hold the tube near the top up against the inside of the ice bucket, keeping the bottom of the tube on ice.

It is good to withdraw some of the fluffy whitish layer underneath the cytoplasmic layer as well, which can be achieved by rotating the needle so that the opening is facing downward.

Expected yield is $\sim 1 \mathrm{~mL}$ of crude cytoplasm from each tube.

13. Supplement the extract with a final concentration of: $10 \mu \mathrm{g} / \mathrm{mL}$ LPC (1:1000 dilution of stock), $10 \mu \mathrm{g} / \mathrm{mL}$ cytochalasin D (1:1000 dilution of stock). Add Energy mix stock at 1:50. Mix by inverting the microfuge tube or pipetting gently with a cut off tip. The freshly prepared extract can be used for $6-8 \mathrm{~h}$.

The final molar concentrations of reagents supplemented to the extract from this step are: $16.67 \mu \mathrm{M} L P C$, $20 \mu \mathrm{m}$ Cytochalasin D, $3.8 \mathrm{mM}$ creatine phosphate, $0.5 \mathrm{~mm} \mathrm{ATP,} 0.5 \mathrm{~mm} \mathrm{MgCl}_{2}$ and $0.05 \mathrm{~mm}$ EGTA. Not all labs supplement the extract with energy mix.

Xenopus tropicalis Egg Extract Procedure

Major differences from X. laevis egg extract preparation accommodate the smaller frog size, its higher physiological temperature, and sensitivity of the eggs to salt.

14. Dilute HCG stock to $100 \mathrm{IU} / \mathrm{mL}$ in sterile MilliQ water and prime X. tropicalis females $20-21 \mathrm{~h}$ before boosting by injecting $250 \mu \mathrm{L}$ ( $25 \mathrm{IU}$ ) HCG subcutaneously into the dorsal lymph sac using a 30-gauge needle and $1 \mathrm{~mL}$ syringe. Store frogs in $6 \mathrm{~L}$ plastic container filled with $4 \mathrm{~L}$ of deionized water.

Typically, six to eight females are used for one extract preparation with a yield of 0.1-0.2 $\mathrm{mL}$ cytoplasm per egg clutch.

Larger tanks are used for $\mathrm{X}$. tropicalis to facilitate squeezing and because they tend to jump.

If working with both X. laevis and X. tropicalis, always use dedicated containers for each species. 
M.C. Good and R. Heald

15. Induce ovulation by boosting primed frogs $\sim 4$ h before extract preparation by injecting $250 \mu \mathrm{L}$ (250 IU) HCG. To control for egg quality, make sure to separate frogs into individual containers filled with deionized water.

Note that the time from boosting injection to ovulation is much shorter than for X. laevis.

16. The first eggs should be laid $2.5-3 \mathrm{~h}$ following the second injection. Once eggs are observed, every 15 min accelerate egg laying by gently clasping each frog and allowing her to kick her legs under the water surface. The frogs will wiggle, which further accelerates egg laying. After four to five "squeezes," analyze egg quality. Good eggs have clearly delineated animal (dark) and vegetal (light) poles. Stringy eggs are okay for X. tropicalis. Clutches of eggs that are activated or lysed (white and puffy appearance) should not be used.

17. Prepare buffers and set up equipment during the clasping period. For eggs from six to eight females, prepare $0.5 \mathrm{~L}$ Dejelly Solution \#2 and $1 \mathrm{~L}$ CSF-XB solution \#2. Ten min before the start of experiments, prepare $50 \mathrm{~mL}$ CSF-XB+ solution \#2, and dispense $1 \mathrm{~mL}$ CSF-XB+ solution \#2 supplemented with $10 \mu \mathrm{L}$ of $10 \mathrm{mg} / \mathrm{mL}$ cytochalasin $\mathrm{D}$ into a single ultracentrifuge tube. For supplies: trim tips from four transfer pipettes to increase opening diameter to $\sim 2 \mathrm{~mm}$, and leave four uncut, gather $4 \mathrm{~L}$ and $500 \mathrm{~mL}$ plastic beakers, and all required reagents and supplies. Make sure that clinical centrifuge is set to $25^{\circ} \mathrm{C}$ and high-speed centrifuge is set to $16^{\circ} \mathrm{C}$.

18. In the next steps (19-21), gently pour buffers down the side of the beaker, and swirl eggs gently to avoid turbulence. Between steps, pour off as much buffer as possible into a $4 \mathrm{~L}$ beaker without exposing the eggs to air, which will lyse them. Manipulate eggs carefully and once eggs are dejellied, carry out subsequent washing and centrifugation steps in rapid succession. Throughout the procedure, remove abnormal or lysed eggs with a transfer pipette.

19. Remove the frogs from the containers. Detach the eggs stuck to the container by gently sweeping them with your gloved finger or by generating water flow using a transfer pipette to put them back into suspension in the water. Before they settle and stick again, combine the best clutches to a single $500 \mathrm{~mL}$ plastic beaker.

Note that eggs stick to some glove brands.

20. Dejelly eggs: pour off remaining water. Add $\sim 250 \mathrm{~mL}$ of Dejelly solution \#2. Swirl the eggs gently, every $20 \mathrm{sec}$, and after $2 \mathrm{~min}$ pour off and replenish dejelly solution. Dejellying is complete once eggs pack together tightly, without gaps, when beaker is tipped to a $45^{\circ}$ angle. Total time to dejelly will vary but should take less than $10 \mathrm{~min}$. Once completed, pour off the dejelly solution and immediately add $250 \mathrm{~mL}$ CSF-XB solution \#2.

21. Wash eggs: Pour off the first addition of CSF-XB solution \#2 and wash several more times with $\sim 250 \mathrm{~mL}$ CSF-XB solution \#2. Pour off as much buffer as possible and add $50 \mathrm{~mL}$ of CSF-XB+ solution \#2. At this point the eggs should be clean and their dark animal poles should be facing up. Sort one final time to remove any bad eggs.

22. Transfer eggs very carefully to prepared ultracentrifuge tube containing CSF-XB+ solution \#2 and cytochalasin. Use trimmed transfer pipette, and avoid exposing the eggs to air by first drawing up $0.5 \mathrm{~mL}$ of CSF-XB+ buffer and then gently drawing up the eggs, and expelling them below the liquid surface.

A single tube can accommodate eggs from six females, and to avoid dilution it is better not to divide eggs into two tubes.

23. Packing spin: Using forceps, place ultracentrifuge tube filled with packed eggs inside a Sarstedt tube. Transfer to a refrigerated clinical centrifuge set to $25^{\circ} \mathrm{C}$. Balance rotor and spin at $500 \mathrm{~g}$ for 1 min, to pack the eggs. After spinning, remove all buffer from the top of the eggs using a transfer pipette.

This step prevents buffer from diluting the cytoplasm, so it is worth sacrificing a few eggs to ensure all buffer is removed. 
24. Crushing spin: Transfer tube filled with packed eggs and balance tube to high-speed centrifuge containing a Sorvall HB-6 rotor with rubber adapters. Crush and fractionate the eggs by centrifuging at $18,000 \mathrm{~g}$ for $15 \mathrm{~min}$ at $16^{\circ} \mathrm{C}$.

25. Collect cytoplasm: Upon completion of centrifugation remove ultracentrifuge tubes from Sarstedt tubes and place them at room temperature or $16^{\circ} \mathrm{C}$. Using an 18 -gauge needle attached to a $1 \mathrm{~mL}$ syringe, puncture the thin-wall tube at the bottom of the cytoplasmic layer and carefully aspirate the cytoplasmic layer without taking up any of the surrounding yolk or lipid layers. Expected yield is $\sim 1 \mathrm{~mL}$ of crude cytoplasm from one tube filled with eggs from six females. Remove the needle and expel the cytoplasm to $1.5 \mathrm{~mL}$ microfuge tube.

26. Supplement the extract with a final concentration of $10 \mu \mathrm{g} / \mathrm{mL}$ LPC (1:1000 dilution of stock), $10 \mu \mathrm{g} / \mathrm{mL}$ cytochalasin D (1:1000 dilution of stock). Add Energy mix stock at 1:50. Mix by inverting the microfuge tube or pipetting gently with a cut off tip. The freshly prepared extract should be kept at $16^{\circ} \mathrm{C}$ and can be used for 5-6 h.

Note that unlike X. laevis egg extracts, X. tropicalis egg extracts should not be placed on ice, as this will compromise activity.

\section{Xenopus laevis Embryo Extract Procedure}

Extracts arrested in mitosis can be prepared from X. laevis embryos through blastula Stage 8, after which cell cycle synchrony is lost. The amount of extract that can be obtained from embryos is much lower than from eggs. Therefore, this procedure has not yet been applied X. tropicalis, due to its smaller egg size and lower yield.

27. Prime $X$. laevis females 3-7 d before performing in vitro fertilization (IVF) by injecting $0.5 \mathrm{~mL}$ (100 IU) of PMSG subcutaneously into the dorsal lymph sac using a 30-gauge needle and $1 \mathrm{~mL}$ syringe.

28. Induce ovulation $14-15 \mathrm{~h}$ before collecting embryos by injecting primed frogs with $0.5 \mathrm{~mL}$ (500 IU) HCG. Store each frog individually in $2 \mathrm{~L}$ of $1 \times$ MMR in a $4 \mathrm{~L}$ plastic container overnight at $16^{\circ} \mathrm{C}$.

Usually three out of four females will lay high-quality eggs, allowing the preparation of three separate singlefrog embryo extracts.

29. Analyze egg quality $14 \mathrm{~h}$ after HCG booster injection. Avoid using females that have laid lysed or stringy eggs, or that have laid no eggs at all.

30. Collect freshly laid eggs: For selected frogs, promote egg-laying by gently squeezing females in a manner that mimics amplexus (Fig. 2A), and collect freshly laid eggs from each frog in individual $6 \mathrm{~cm}$ glass dishes that have been coated with $\sim 5 \mathrm{~mL}$ of $1.5 \%$ agarose in $0.1 \times$ MMR. Repeat every $15 \mathrm{~min}$ (up to four total squeezes) or until each dish is full. Place females in deionized water in between rounds of egg collection.

31. Prepare sperm slurry: For each IVF reaction, use $1 / 8$ of a testis recently isolated from a Xenopus male (see Protocol: Isolation and Demembranation of Xenopus Sperm Nuclei [Hazel and Gatlin 2018]). Use scissors to cut the testis into appropriately sized pieces, and place each in its own $1.5 \mathrm{~mL}$ microfuge tube containing $1 \mathrm{~mL}$ of MilliQ $\mathrm{H}_{2} \mathrm{O}$. Crush each piece using a plastic pestle for $1-2 \mathrm{~min}$.

Testes can be used for up to 1-2 wk following dissection, but fertilization efficiency may drop over time.

32. Fertilize eggs: For each IVF reaction in a separate dish, pipette $1 \mathrm{~mL}$ of a slurry that contains approximately one eighth of a testis onto the eggs and incubate for $5-10 \mathrm{~min}$ at $16^{\circ} \mathrm{C}$. Flood each dish with $0.1 \times$ MMR and incubate an additional 10-20 min or until all of the zygotes have rotated so that the animal cap (dark) is facing up (Fig. 2B), indicating successful fertilization.

33. Dejelly eggs: This should be performed just after rotation, $\sim 15$ min postfertilization, and before the first cleavage, which occurs at $\sim 90 \mathrm{~min}$. Pour off $0.1 \times$ MMR and add $20 \mathrm{~mL}$ of freshly prepared Dejelly solution \#2 to each dish. Swirl gently for 2-3 min, until embryos pack tightly 
M.C. Good and R. Heald

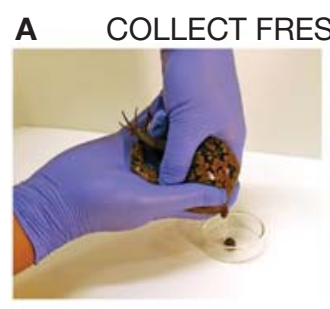

C

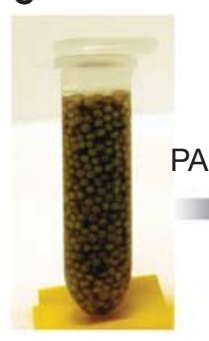

Dejellied

Embryos

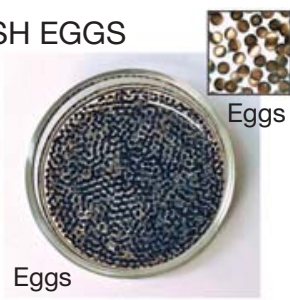

D

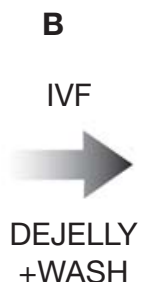

+ WASH
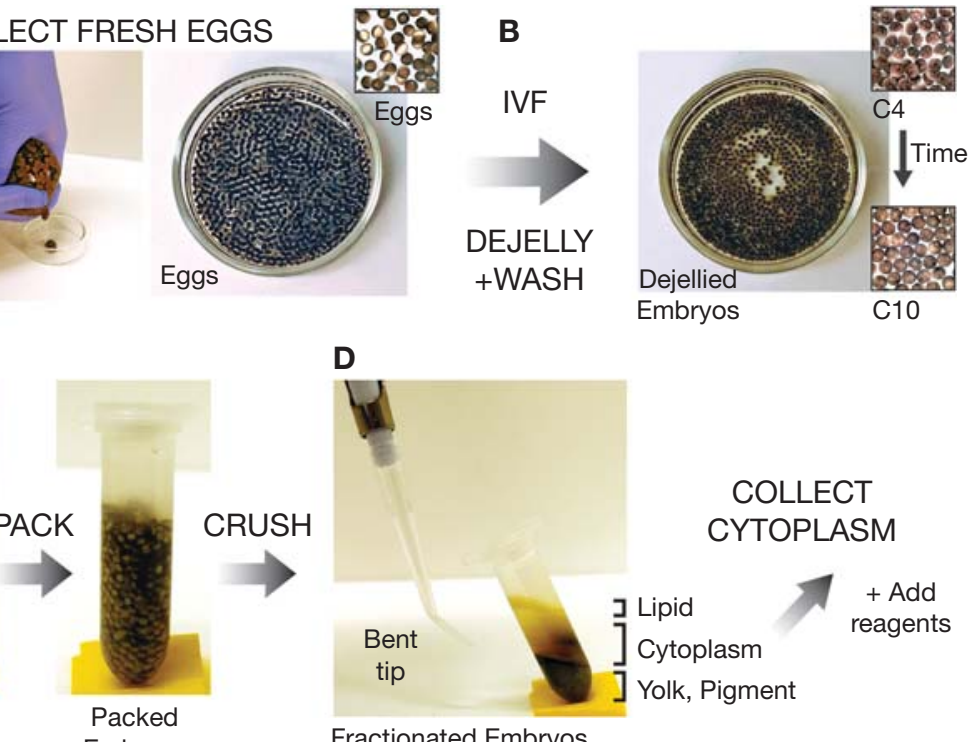

Fractionated Embryos

FIGURE 2. Xenopus laevis embryo extract preparation. (A) In contrast to egg extracts which can be prepared from laid eggs, embryo extracts require freshly squeezed eggs. (B) Eggs are fertilized by sperm in vitro and subsequently dejellied before the first embryonic division. Embryos are synchronized and collected at specific developmental stages. Inset shows embryos that have undergone four cell divisions (C4) or 10 divisions (C10). (C) Dejellied embryos are packed tightly together by centrifugation to remove excess buffer. These packed embryos are then crushed and fractionated by high-speed centrifugation. $(D)$ The cytoplasm layer is collected by threading a bent pipette tip through the lipid layer, and supplemented with reagents to generate the final crude embryo cytoplasm.

together when dish is tilted. Pour off Dejelly solution and wash 3-5 times with $0.1 \times$ MMR. Add $15 \mathrm{~mL} 0.1 \times \mathrm{MMR}$ and continue incubation. Let embryo development progress at $16^{\circ} \mathrm{C}$ until the desired developmental state.

At room temperature the first cytokinesis should take place $\sim 90$ min post fertilization.

At $16^{\circ} \mathrm{C}$, embryos reach mid-Stage 4 at $\sim 4.5 \mathrm{~h}$, or mid-Stage 8 at $\sim 13.5 \mathrm{~h}$.

34. Sort embryos: Using a dissecting stereomicroscope, transfer embryos that are cleaving nicely to a fresh dish coated in $1.5 \%$ agarose in $0.1 \times$ MMR. Continue to monitor developmental progression by recording the timing of the second and third divisions. Remove embryos that are lagging or beginning to lyse.

35. Prepare remaining buffers and carry out final sort $30 \mathrm{~min}$ before appropriate time point for embryo collection. Prepare $0.2 \mathrm{~L}$ of XB solution, and $100 \mathrm{~mL}$ of CSF-XB+ supplemented with $100 \mu \mathrm{L}$ of $10 \mathrm{mg} / \mathrm{mL}$ cytochalasin D. Perform final sort to ensure that the remaining $\sim 1000$ embryos in each dish are homogeneous.

36. Wash embryos: Pour off $0.1 \times$ MMR and add in succession to each dish: $2 \times 25 \mathrm{~mL}$ of $\mathrm{XB}$, then $2 \times 15 \mathrm{~mL}$ of CSF-XB+ with cytochalasin. Gently swirl and pour off buffers between each addition. Tilt dish so that surface tension helps to carefully pull the solution over the lip of the dish. This ensures that embryos will not be poured off during buffer exchanges.

37. Pack embryos: After pouring off remaining buffer, and without exposing embryos to air, carefully transfer the embryos from a single dish into a $2 \mathrm{~mL}$ microfuge tube using a cut transfer pipette. A full dish of embryos, unpacked, will fill the tube to a level of $\sim 1.7 \mathrm{~mL}$ (Fig. $2 \mathrm{C}$ ). Centrifuge at $200 \mathrm{~g}$ for $1 \mathrm{~min}$ and then at $500 \mathrm{~g}$ for $30 \mathrm{sec}$ in a benchtop microcentrifuge at room temperature. Remove remaining buffer with a pipette, first using a P1000 and then a P200 tip. 
38. Crush embryos: Transfer $2 \mathrm{~mL}$ tubes containing packed eggs to a Sorvall HB-6 rotor containing microfuge tube adapters, in a superspeed centrifuge set to $16^{\circ} \mathrm{C}$. Centrifuge at $18,000 \mathrm{~g}$ for $12 \mathrm{~min}$. Alternatively, eggs can be crushed by spinning for 12 min at 18,000g using a benchtop refrigerated microcentrifuge set to $16^{\circ} \mathrm{C}$.

39. Collect embryo cytoplasm: After crushing the embryos into stratified layers, place the $2 \mathrm{~mL}$ microfuge tube on ice. Using a bent P200 pipette tip (Fig. 2D), insert the tip from above, through the lipid layer and carefully withdraw the cytoplasm, making sure to avoid surrounding layers. Dispense the cytoplasm into a prechilled $1.5 \mathrm{~mL}$ microfuge tube. Expect a yield of $\sim 400$ $500 \mu \mathrm{L}$ of crude cytoplasm for each full dish of embryos. The layers correspond to, top: lipid (white-yellow), middle: cytoplasm (gold), bottom: yolk granules and pigment (black/brown) (Fig. 2D).

40. Supplement the embryo extract with a final concentration of $10 \mu \mathrm{g} / \mathrm{mL}$ LPC (1:1000 dilution of stock) and $10 \mu \mathrm{g} / \mathrm{mL}$ cytochalasin D (1:1000 dilution of stock). Add Energy mix at 1:50. Mix by inverting the microfuge tube. To ensure that the extracts are synchronized and arrested in mitosis, add a nondegradable form of cyclin $\mathrm{B}$ along with a dominant-negative form of the ubiquitinating E2, UbcH10 (UbcH10-C114s), to final concentrations of $\sim 0.35 \mu \mathrm{M} \Delta 90$-CyclinB1 and $\sim 18 \mu \mathrm{M}$ UbcH10-C114S. Mix by inverting tube or pipetting gently with a cut off tip. Embryo extracts stored on ice are functional for up to $6 \mathrm{~h}$.

To further enhance metaphase arrest and improve spindle forming activity, the embryo can be supplemented with 5\%-10\% CSF-arrested cytoplasmic egg extract from Xenopus laevis (Good 2016).

These procedures are based on the method first described by Lohka and Masui (Lohka and Maller 1985; Lohka and Masui 1983), optimized initially by Andrew Murray (Murray 1991) and further refined over the years (Desai et al. 1998; Maresca and Heald 2006; Good 2016). Central to the success of all extract preparations is the quality of the eggs. Crude or further fractionated Xenopus laevis egg extract have been used widely for a variety of protocols. A major strength of in vitro systems such as these comes from the ability to manipulate them biochemically by immunodepletion or by adding recombinant proteins or fluorescent probes.

Xenopus tropicalis frogs are considerably smaller than their X. laevis relative, and lay proportionally smaller eggs. Therefore, they are less suitable for generating the large volumes of egg extract that form the basis of many assays. However, the observation that the size of nuclei and spindles formed in $X$. tropicalis egg extract are smaller than those formed in X. laevis and recapitulate in vivo differences has uniquely enabled investigation of mechanisms of intracellular scaling between species (Brown et al. 2007).

Extracts prepared from $X$. laevis embryos must be arrested in metaphase using exogenously added regulators of the cell cycle machinery. Cyclin B $\Delta 90$ is a nondegradable version of cyclin that activates Cdk1 (Glotzer et al. 1991). Mitotic arrest is further enhanced by addition of UbcH10-C114S, which functions as a dominant negative inhibitor of the Anaphase Promoting Complex (APC) (Townsley et al. 1997; Rape et al. 2006). These extracts have been used to compare spindle morphologies between meiosis and the early mitotic divisions (Wuhr et al. 2008; Wilbur and Heald 2013), and formed the basis of assays to examine spindle scaling during development (Wuhr et al. 2008; Good et al. 2013; Wilbur and Heald 2013). Embryo extracts have also been prepared that are arrested in interphase that enable investigation of nuclear scaling (Levy and Heald 2010). Like egg extracts, embryo extracts largely recapitulate in vivo size differences, but can be prepared only in very small amounts. Their activity is therefore reduced compared to egg extracts, likely due in part to increased dilution of the cytoplasm with buffer. 
CSF-XB

\begin{tabular}{lc} 
Reagent & Quantity \\
\hline XB (extract buffer) $<\mathrm{R}>$ & $400 \mathrm{~mL}$ \\
$\begin{array}{l}\text { EGTA stock (K salt; } 0.5 \mathrm{M} \text {; pH 7.7; filter-sterilized and stored in } \\
\left.\quad \text { aliquots at }-20^{\circ} \mathrm{C}\right)\end{array}$ & $4 \mathrm{~mL}$ \\
$\mathrm{MgCl}_{2}$ solution $(2 \mathrm{M}$; e.g., Sigma-Aldrich 68475) & $200 \mu \mathrm{L}$
\end{tabular}

Make fresh on the day of extract preparation.

CSF-XB Solution \#2 for X. tropicalis Eggs

Reagent

Volume

Extract Buffer $(\mathrm{XB})$ salts $(20 \times)<\mathrm{R}>$

$50 \mathrm{~mL}$

Sucrose $\left(2 \mathrm{M}\right.$; filter-sterilized and stored in aliquots at $\left.-20^{\circ} \mathrm{C}\right) \quad 25 \mathrm{~mL}$

$\mathrm{K}$-HEPES ( $1 \mathrm{M}$; K salt; pH 7.7; filter-sterilized and stored in aliquots $10 \mathrm{~mL}$ at $-20^{\circ} \mathrm{C}$ )

$\mathrm{MgCl}_{2}$ (2 M; e.g., Sigma-Aldrich 68475) $1 \mathrm{~mL}$

EGTA $(0.5 \mathrm{M}$; K salt; pH 7.7; filter-sterilized and stored in aliquots $20 \mathrm{~mL}$ at $-20^{\circ} \mathrm{C}$ )

Make fresh on the day of extract preparation. Combine and bring to $1 \mathrm{~L}$ with MilliQ $\mathrm{H}_{2} \mathrm{O}$. Adjust $\mathrm{pH}$ to 7.7 with $\mathrm{KOH}$.

Dejelly Solution \#1 for X. laevis Eggs

\begin{tabular}{lrc} 
Reagent & Quantity & Concentration \\
\hline L-cysteine (e.g., Sigma-Aldrich C7352) & $20 \mathrm{~g}$ & $2 \%$ \\
Extract buffer $(\mathrm{XB})$ salts $(20 \times)<\mathrm{R}>$ & $50 \mathrm{~mL}$ & $1 \times$
\end{tabular}

Combine with $900-\mathrm{mL}$ MilliQ $\mathrm{H}_{2} \mathrm{O}$, adjust $\mathrm{pH}$ to 7.8 with $10-\mathrm{M} \mathrm{NaOH}$, and bring to $1 \mathrm{~L}$ with MilliQ $\mathrm{H}_{2} \mathrm{O}$. Make fresh on day of preparation, and store at $16^{\circ} \mathrm{C}$ until use.

Dejelly Solution \#2 for X. tropicalis Eggs and X. laevis Embryos

Combine $15 \mathrm{~g}$ of L-cysteine (e.g., Sigma-Aldrich C-7352) with 450-mL MilliQ $\mathrm{H}_{2} \mathrm{O}$. Adjust the $\mathrm{pH}$ to 7.8 with $\mathrm{NaOH}$, and bring to $0.5 \mathrm{~L}$ (to make a $3 \% \mathrm{~L}$ cysteine solution). Make fresh on day of prep and store at room temperature until use.

Energy Mix (50×)

Reagent Quantity

Creatine phosphate disodium salt tetrahydrate (MW 327.14) $0.622 \mathrm{~g}$

Adenosine $5^{\prime}$-triphosphate (ATP) disodium salt hydrate $0.138 \mathrm{~g}$ (MW 511.14)

EGTA stock ( $\mathrm{K}$ salt; $0.5 \mathrm{M}$; pH 7.7; filter-sterilized and stored in $\quad 0.05 \mathrm{~mL}$ aliquots at $\left.-20^{\circ} \mathrm{C}\right)$

$\mathrm{MgCl}_{2}$ stock (2 M; e.g., Sigma-Aldrich 68475) $0.125 \mathrm{~mL}$

Combine with MilliQ $\mathrm{H}_{2} \mathrm{O}$ to a volume of $10 \mathrm{~mL}$. Make $0.1-\mathrm{mL}$ aliquots, and store at $-20^{\circ} \mathrm{C}$. 
Extract Buffer (XB) Salts (20x)

\begin{tabular}{lrr} 
Reagent & Quantity & Concentration \\
\hline $\mathrm{KCl}$ & $149.12 \mathrm{~g}$ & $2 \mathrm{M}$ \\
$\mathrm{CaCl}_{2}$ & $0.294 \mathrm{~g}$ & $2 \mathrm{mM}$ \\
$\mathrm{MgCl}_{2}$ (2 м; e.g., Sigma-Aldrich 68475) & $10 \mathrm{~mL}$ & $20 \mathrm{~mm}$
\end{tabular}

Combine with MilliQ $\mathrm{H}_{2} \mathrm{O}$ to a volume of $1 \mathrm{~L}$. Autoclave and store at $4^{\circ} \mathrm{C}$.

Marc's Modified Ringer's (MMR; 20x)

Reagent Quantity

Final concentration

$\begin{array}{lrr}\text { HEPES, free acid } & 95.32 \mathrm{~g} & 100 \mathrm{~mm} \\ \mathrm{EDTA} & 2.98 \mathrm{~g} & 2 \mathrm{~mm} \\ \mathrm{NaCl} & 467.52 \mathrm{~g} & 2 \mathrm{M} \\ \mathrm{KCl} & 11.93 \mathrm{~g} & 40 \mathrm{~mm} \\ \mathrm{CaCl}_{2} & 23.52 \mathrm{~g} & 40 \mathrm{~mm} \\ \mathrm{MgCl}_{2} \text { (e.g., Sigma-Aldrich } & 40 \mathrm{~mL} \text { of } 2 \mathrm{M} \text { stock } & 20 \mathrm{mM}\end{array}$
68475)

Combine with MilliQ $\mathrm{H}_{2} \mathrm{O}$, adjust $\mathrm{pH}$ to $7.8-7.9$ using $\sim 8.5 \mathrm{~g}$ of $\mathrm{NaOH}$ pellets, and bring to $4 \mathrm{~L}$. Autoclave and store at room temperature.

\section{XB (Extract Buffer)}

Reagent

Extract buffer $(\mathrm{XB})$ salts $(20 \times)<\mathrm{R}>$

Sucrose $\left(2 \mathrm{M}\right.$; filter-sterilized and stored in aliquots at $\left.-20^{\circ} \mathrm{C}\right)$

HEPES (K salt; $1 \mathrm{M}, \mathrm{pH} 7.7$; filter-sterilized and stored in aliquots at $\left.-20^{\circ} \mathrm{C}\right)$

Combine and bring to $1 \mathrm{~L}$ with MilliQ $\mathrm{H}_{2} \mathrm{O}$. Adjust $\mathrm{pH}$ to 7.7 with $\mathrm{KOH}$. Make fresh on day of preparation, and store at $16^{\circ} \mathrm{C}$ until use.

Volume

$50 \mathrm{~mL}$

$25 \mathrm{~mL}$

$10 \mathrm{~mL}$ 西

We thank Romain Gibeaux and Lily Einstein for helpful comments on the manuscript. Work in our laboratories is supported by National Institutes of Health (NIH) R35 GM118183 (R.H.) and a Burroughs Wellcome Fund Career Award (M.C.G.).

\section{REFERENCES}

Brown KS, Blower MD, Maresca TJ, Grammer TC, Harland RM, Heald R. 2007. Xenopus tropicalis egg extracts provide insight into scaling of the mitotic spindle. J Cell Biol 176: 765-770.

Desai A, Murray A, Mitchison TJ, Walczak CE. 1998. The use of Xenopus egg extracts to study mitotic spindle assembly and function in vitro. Methods Cell Biol 61: 385-412.

Glotzer M, Murray AW, Kirschner MW. 1991. Cyclin is degraded by the ubiquitin pathway. Nature 349: 132-138.

Good MC. 2016. Encapsulation of Xenopus egg and embryo extract spindle assembly reactions in synthetic cell-like compartments with tunable size. Methods Mol Biol 1413: 87-108.

Good MC, Vahey MD, Skandarajah A, Fletcher DA, Heald R. 2013. Cytoplasmic volume modulates spindle size during embryogenesis. Science 342: 856-860.

Hazel JW, Gatlin JC. 2018. Isolation and demembranation of Xenopus sperm nuclei. Cold Spring Harb Protoc doi: 10.1101/pdb.prot099044.

Levy DL, Heald R. 2010. Nuclear size is regulated by importin $\alpha$ and Ntf2 in Xenopus. Cell 143: 288-298.

Lohka MJ, Maller JL. 1985. Induction of nuclear envelope breakdown, chromosome condensation, and spindle formation in cell-free extracts. J Cell Biol 101: 518-523. 


\section{Preparation of Cellular Extracts from Xenopus Eggs and Embryos}

Matthew C. Good and Rebecca Heald

Cold Spring Harb Protoc; doi: 10.1101/pdb.prot097055 originally published online February 7, 2018

\begin{tabular}{cc}
$\begin{array}{r}\text { Email Alerting } \\
\text { Service }\end{array}$ & Receive free email alerts when new articles cite this article - click here. \\
\hline $\begin{array}{c}\text { Subject } \\
\text { Categories }\end{array}$ & $\begin{array}{c}\text { Browse articles on similar topics from Cold Spring Harbor Protocols. } \\
\text { Cell Biology, general (1382 articles) } \\
\text { Developmental Biology (728 articles) } \\
\text { Subcellular Fractionation (88 articles) } \\
\text { Xenopus (210 articles) }\end{array}$ \\
\hline
\end{tabular}

